\title{
Association between social participation and hypertension among older people in Japan: the JAGES Study
}

\begin{abstract}
Aki Yazawa ${ }^{1}$, Yosuke Inoue ${ }^{1}$, Takeo Fujiwara ${ }^{2}$, Andrew Stickley ${ }^{1,3}$, Kokoro Shirai $^{4}$, Airi Amemiya ${ }^{2}$, Naoki Kondo ${ }^{5,6}$, Chiho Watanabe ${ }^{1}$ and Katsunori Kondo ${ }^{7,8}$

Hypertension is an important risk factor for cardiovascular disease, the leading cause of mortality in the world. Although previous studies have focused on individual-level behavioral risk factors associated with hypertension, there has been little research on how interacting with others, that is social participation, affects hypertension. To address this research gap, this study examined the association between social participation and hypertension in Japan, a country with a high prevalence of hypertension possibly linked to rapid population aging. Data were used from 4582 participants aged more than 65 years who participated in the Japan Gerontological Evaluation Survey (JAGES) with blood pressure data collected during a health check-up. The frequency of participation in vertical organizations (characterized by hierarchical relationships) and horizontal organizations (characterized by non-hierarchical, egalitarian relationships) was measured by a questionnaire. In a Poisson regression analysis, participation in vertical organizations was not associated with hypertension, whereas participation in horizontal organizations at least once a month was inversely associated with hypertension (prevalence ratio: 0.941). This association remained significant after adjusting for social support variables, although further adjustment for health behaviors attenuated the association. As the frequency of going out and average time spent walking were both associated with hypertension, physical activity may be a possible pathway that connects social participation and hypertension. The results of this study suggest that expanding social participation programs, especially those involving horizontal organizations, may be one way to promote better health among older people in Japan.
\end{abstract}

Hypertension Research (2016) 39, 818-824; doi:10.1038/hr.2016.78; published online 7 July 2016

Keywords: blood pressure; gerontology; social determinants of health

\section{INTRODUCTION}

Cardiovascular diseases are the leading cause of mortality in the world. ${ }^{1}$ As both high systolic and diastolic blood pressure are associated with cardiovascular disease, hypertension has been identified as one of the most important risk factors for cardiovascular disease. ${ }^{2,3}$ Hypertension already affects one billion people worldwide ${ }^{4}$ and it is estimated that this will increase further to 1.56 billion by $2025 .^{5}$

Previous studies that have examined the factors associated with hypertension have focused on health-related behavioral factors such as unhealthy diet, harmful use of alcohol and physical inactivity. ${ }^{4}$ However, there has been comparatively little focus on how individuals' interaction with their surrounding environment might affect hypertension. For example, little is known about the effects of social participation (that is, participation in community organizations).

The concept of social participation, which refers to involvement in the activities of formal and informal societal groups, ${ }^{6}$ has become one of the areas of focus in the attempt to create age-friendly cities. ${ }^{7}$ It has been linked to improved health via two potential pathways: health behavior and psychological stress. ${ }^{8}$ In terms of the former, social participation is believed to affect health behaviors, as individuals receive behavioral guidance through interaction with their network members, ${ }^{9,10}$ while groups' social control mechanisms can both encourage and discourage good (for example, exercise, diet) and bad (for example, smoking) health behaviors, respectively. ${ }^{11}$ Moreover, research suggests that in some organizations, physical activity levels and, possibly, alcohol consumption can also be elevated as a result of

${ }^{1}$ Department of Human Ecology, Graduate School of Medicine, The University of Tokyo, Tokyo, Japan; ${ }^{2}$ Department of Social Medicine, National Center for Child Health and Development, Tokyo, Japan; ${ }^{3}$ The Stockholm Center for Health and Social Change (Scohost), Södertörn University, Stockholm, Sweden; ${ }^{4}$ Department of Human Sciences, School of Law and Letters, University of the Ryukyus, Okinawa, Japan; ${ }^{5}$ Department of Health and Social Behavior, School of Public Health, The University of Tokyo, Tokyo, Japan; ${ }^{6}$ Department of Health Education and Health Sociology, School of Public Health, The University of Tokyo, Tokyo, Japan; ${ }^{7}$ Center for Preventive Medical Sciences, Chiba University, Chiba, Japan and ${ }^{8}$ Center for Well-being and Society, Nihon Fukushi University, Aichi, Japan

Correspondence: A Yazawa, Department of Human Ecology, Graduate School of Medicine, The University of Tokyo, 7-3-1 Hongo, Bunkyo, Tokyo 113-0033, Japan.

E-mail: aki-y@humeco.m.u-tokyo.ac.jp

Received 28 March 2016; revised 6 May 2016; accepted 29 May 2016; published online 7 July 2016 
participating in social activities. ${ }^{12,13}$ For the latter, it has been suggested that social participation may enhance people's ability to cope with stressors by increasing the sense of companionship and belonging they feel. ${ }^{10,14} \mathrm{~A}$ number of studies have shown that social participation is associated with both a lower mortality risk ${ }^{15-19}$ and measures of well-being such as better self-rated health, ${ }^{20-22}$ although not all studies have found an association with health. ${ }^{23,24}$

Until now, few studies have examined the association between social participation and hypertension, while those studies which have been undertaken have produced conflicting findings. Kamiya et al. ${ }^{25}$ used data from the English Longitudinal Study of Ageing (ELSA) and found that participating in a greater number of organizations (summed from 0 to 7 ) was associated with lower odds for hypertension. Shankar et al. ${ }^{26}$ also used data from the same cohort to show that greater social isolation, as measured by a cumulative score of social participation, marital status and contact with family and friends, was associated with a significant increase in systolic blood pressure and diastolic blood pressure. In contrast, a study using US nationally representative data found that social participation (that is, attending church, meetings and belonging to clubs) was not associated with differences in blood pressure. $^{27}$

To the best of our knowledge, no previous study has focused on the association between social participation and hypertension in a nonWestern setting. This may be an important research gap especially as some evidence suggests that the determinants and distribution of cardiovascular disease may differ in non-Western countries owing to differences in the social environment, lifestyle or genetic factors. ${ }^{28}$ There is also a need to determine whether different forms of individual activity might be reflected in different health effects in this context. Specifically, when focusing on the structure of relationships, earlier research in Japan has indicated that participating in 'horizontal' organizations (characterized by non-hierarchical, egalitarian relationships) may have a more beneficial effect on health, compared with participating in 'vertical' organizations (characterized by hierarchical relationships). ${ }^{8}$

In the current study, we used data from the Japan Gerontological Evaluation Survey (JAGES) to investigate the association between social participation and hypertension among individuals aged 65 years or older, while paying particular attention to two different types of social participation (that is, participation in vertical and horizontal organizations). Determining the exact effects of these different forms of social participation on health may be important for future attempts to enhance the well-being of older people in Japan, especially as the Japanese government has promoted social participation programs among older people as a key element in creating a healthy aging society. ${ }^{29}$

\section{METHODS}

\section{Data}

The JAGES project is an ongoing prospective epidemiological study examining the social determinants of health among older people in Japan (focusing on those who are not certified as needing long-term care services). As a part of the JAGES project, the current study used both questionnaire data collected in one of the JAGES survey waves (2010) and medical data that were obtained during a municipality-managed health examination, the Tokutei kenkou shinsa (Kenshin), in 2010. The data were provided by local municipalities and were linked with postal questionnaire data collected in August 2010 from individuals in six municipalities in Chita peninsula, Aichi. From the 20432 people who participated in the JAGES study in Aichi prefecture, health examination data were linked for 9893 (48.4\%) and information on blood pressure was provided by four municipalities $(n=6597)$. After excluding those who lacked information on social participation $(n=1974)$ or whose body mass index was less than
15 or more than $40(n=41)$, a total of 4582 participants were included in the subsequent analyses.

\section{Dependent variable}

Blood pressure was measured at community health centers or registered hospitals by trained nurses. Participants were recommended to rest for more than $5 \mathrm{~min}$ prior to the first measurement, which was taken in a sitting position. This was then followed by a second measurement after a 1-min rest and the average value from the two measurements was recorded as instructed by the Ministry of Health, Labour and Welfare, Japan..$^{30}$ Using the Japanese Society of Hypertension guidelines, participants were categorized as hypertensive (i) when their systolic blood pressure was equal to or higher than $140 \mathrm{~mm} \mathrm{Hg}$ or (ii) diastolic blood pressure was equal to or higher than $90 \mathrm{~mm} \mathrm{Hg}$, or (iii) if they responded positively to questions on current use of antihypertensive medication in the postal questionnaire or at the health check-up. ${ }^{31}$

\section{Independent variables}

Social participation was assessed in the JAGES questionnaire by asking the respondents about how frequently they participated in the following eight types of organization, that is, (i) political groups, (ii) industry group/trade associations, (iii) volunteer groups, (iv) religious groups, (v) sports groups, (vi) neighborhood associations, (vii) senior citizens' clubs and (viii) hobby groups. Following the lead of an earlier study, those who participated in any of these organizations once a month or more often were categorized as having a higher level of social participation. ${ }^{32}$ Further focusing on the different nature of these eight organizations, we then divided them into two organizational forms (that is, vertical organizations and horizontal organizations). This was based on the findings of a previous study which used principal components analysis on data from the same cohort collected in 2003 to categorize these organizational forms. ${ }^{8}$ Vertical organizations included political, industry/trade and religious groups, neighborhood associations and senior citizen's clubs; horizontal organizations included volunteer, sports and hobby groups.

\section{Covariates}

Demographic and socioeconomic covariates included age in years, sex and body mass index $\left(\mathrm{kg} \mathrm{m}^{-2}\right)$, which was divided into four categories (underweight: $<18.5$; normal weight: $18.5-24.9$; overweight: $25-29.9$; obese: $\geqslant 30$ ), years of education ( $<10$ years; $10-12$ years; $>12$ years), marital status (currently married or not), and equivalent annual income ( $<$ two million yen; two to four million yen; > four million yen). Height and weight were measured during the health check-up.

Social support to/from neighbors or friends was also included as a covariate in the analysis; we inquired whether either emotional or instrumental social support was provided or received by asking the following questions; 'Do you have someone who listens to your concerns and complaints?', 'Do you listen to someone's concerns and complaints?', 'Do you have someone who looks after you when you are sick and confined to bed for a few days?' and 'Do you look after someone when he/she is sick and confined to bed for a few days?'. If participants either provided and/or received social support from neighbors or friends, they were scored ' 1 ', whereas those who did not provide/receive support were scored ' 0 '.

To examine the effects of health behaviors, information was obtained on the frequency of alcohol consumption (never, rarely, one to three days a week, four to six days a week, every day) and smoking status (0: do not smoke; 1: currently smoke; 2: have stopped smoking). For physical activity, two measures were used. The frequency of going outside was divided into three categories: almost every day; one to three times a week; and once or twice a month or less often. The average time spent walking each day was also classified in three categories: $<30 \mathrm{~min} ; 30-59 \mathrm{~min}$; and $\geqslant 60 \mathrm{~min}$.

Respondents' mental health was assessed using the 15-item Geriatric Depression Scale (GDS). ${ }^{33}$ This instrument categorizes respondents into three groups, that is, no depression (0-4), mild depression (5-9) and depression (10-15). Sense of coherence (SOC), which has been shown to influence the ability to cope with stressful life experiences, ${ }^{34}$ and has previously been found to be associated with blood pressure, ${ }^{35}$ was measured using six questions in this 
Table 1 Characteristics of the study participants $(N=4582)$

$\begin{array}{cc}\begin{array}{c}\text { People with } \\ \text { hypertension } \\ (\mathrm{n}=2728)\end{array} & \begin{array}{c}\text { People without } \\ \text { hypertension } \\ (\mathrm{n}=1854)\end{array}\end{array} \quad$ Total $(\mathrm{N}=4582)$

n (\%)/Mean (s.d.) n (\%)/Mean (s.d.) n (\%)/Mean (s.d.)

\begin{tabular}{lccc}
\hline Age & $72.3(5.4)$ & $70.8(4.7)$ & $71.7(5.2)$ \\
Sex (\% female) & $1354(49.6)$ & $929(50.1)$ & $2283(49.8)$
\end{tabular}

Equivalent annual income (million yen)

$\begin{array}{lclc}<2.00 & 1114(40.8) & 735(39.6) & 1849(40.4) \\ 2.00-4.00 & 1006(36.9) & 743(40.1) & 1749(38.2) \\ >4.00 & 209(7.7) & 142(7.7) & 351(7.7)\end{array}$

Years of education

10-12 years

$1318(48.3)$

$784(42.3)$

More than 12 years

974 (35.7)

Other

$331(12.1)$

$13(0.5)$

$712(38.4)$

$291(15.7)$

$13(0.7)$

$2102(45.9)$

$1686(36.8)$

$622(13.6)$

$26(0.6)$

\section{Marital status \\ Has a partner \\ No partner \\ Other}

$2072(76.0)$

$557(20.4)$

$8(0.3)$

Body mass index

15-18.4

$18.5-24.9$

$100(3.7)$

$1801(66.0)$

25-29.9

$747(27.4)$

30-40

80 (2.9)

Social participation

Yes

1416 (51.9)

$1312(48.1)$

$1092(58.9)$

No

$762(41.1)$

Participation in vertical organizations

Yes $632(23.2)$

No $2096(76.8)$

$461(24.9)$

$1393(75.1)$

Participation in horizontal organizations

Yes $1218(44.7)$

No

$1510(55.4)$

$961(51.8)$

$893(48.2)$

$2179(47.6)$

$2403(52.4)$

Providing emotional support

Yes $1251(45.9)$

No $\quad 1435$ (52.6)

$912(49.2)$

$922(49.7)$

Receiving emotional support

Yes

$346(12.7)$

$217(11.7)$

3568 (77.9)

855 (18.7)

$12(0.3)$

$252(5.5)$

$3197(69.8)$

1036 (22.6)

$97(2.1)$

$2508(54.7)$

$2074(45.3)$

1093 (23.9)

$3489(76.2)$

No

$2360(86.5)$

Providing instrumental support

Yes

237 (8.7)

No

$2425(88.9)$

$191(10.3)$

$1643(88.6)$

Receiving instrumental support

Yes

$162(5.9)$

$129(7.0)$

$1718(92.7)$

$291(6.4)$

$4260(93.0)$

Geriatric Depression Scale score

$\begin{array}{lr}\text { No depression } & 1749(64.1) \\ \text { Mild depression } & 480(17.6) \\ \text { Depression } & 134(4.9)\end{array}$

$1221(65.9)$

$303(16.3)$

$76(4.1)$

$2970(64.8)$

$783(17.1)$

$210(4.6)$
Table 1 (Continued)

\begin{tabular}{|c|c|c|c|}
\hline & $\begin{array}{l}\text { People with } \\
\text { hypertension } \\
(n=2728)\end{array}$ & $\begin{array}{c}\text { People without } \\
\text { hypertension } \\
(\mathrm{n}=1854)\end{array}$ & Total $(\mathrm{N}=4582)$ \\
\hline & n (\%)/Mean (s.d.) & $\mathrm{n}(\%) /$ Mean (s.d.) & n (\%)/Mean (s.d.) \\
\hline \multicolumn{4}{|l|}{ Sense of coherence score } \\
\hline Low & $832(30.5)$ & $536(28.9)$ & $1368(29.9)$ \\
\hline Middle & $658(24.1)$ & $468(25.2)$ & $1126(24.6)$ \\
\hline High & $1017(37.3)$ & $716(38.6)$ & $1733(37.8)$ \\
\hline \multicolumn{4}{|l|}{ Frequency of going outside } \\
\hline $\begin{array}{l}\text { Once to twice a month } \\
\text { or less }\end{array}$ & $136(5.0)$ & $55(3.0)$ & $191(4.2)$ \\
\hline $\begin{array}{l}\text { One to three times a } \\
\text { week }\end{array}$ & 925 (33.9) & $619(33.4)$ & $1544(33.7)$ \\
\hline Almost every day & $1513(55.5)$ & $1090(58.8)$ & $2603(56.8)$ \\
\hline \multicolumn{4}{|c|}{ Average time spent walking each day } \\
\hline Less than $30 \mathrm{~min}$ & $845(31.0)$ & $474(25.6)$ & $1319(28.8)$ \\
\hline $30-59 \mathrm{~min}$ & $951(34.9)$ & $654(35.3)$ & $1605(35)$ \\
\hline 60 min or more & $868(31.8)$ & $695(37.5)$ & $1563(34.1)$ \\
\hline \multicolumn{4}{|l|}{ Smoking } \\
\hline Never smoked & $1803(66.1)$ & $1116(60.2)$ & $2919(63.7)$ \\
\hline Currently smoke & $209(7.7)$ & $163(8.8)$ & $372(8.1)$ \\
\hline $\begin{array}{l}\text { Have stopped } \\
\text { smoking }\end{array}$ & $370(13.6)$ & $188(10.1)$ & $558(12.2)$ \\
\hline \multicolumn{4}{|l|}{ Alcohol consumption } \\
\hline Never & $852(31.2)$ & $520(28.1)$ & 746 (29.9) \\
\hline Rarely & $616(22.6)$ & $426(23.0)$ & $1042(22.8)$ \\
\hline 1-3 days a week & $262(9.6)$ & $172(9.3)$ & $434(9.5)$ \\
\hline 4-6 days a week & $125(4.6)$ & $62(3.3)$ & $187(4.1)$ \\
\hline Every day & 516 (18.9) & $285(15.4)$ & $801(17.5)$ \\
\hline
\end{tabular}

study (two questions from each of the three sub-domains used in Antonovsky's Sense of Coherence Scale). ${ }^{36}$ The questions selected were: 'Do you feel you are treated unfairly?', 'Does what you do every day give you pleasure and satisfaction?', 'Do you feel confused with your feeling or thinking?', 'Do you experience undesired emotions?', 'Do you feel what you do every day has little meaning to you?' and 'Do you lose confidence in your ability to keep self-control?'(Cronbach's alpha $=0.83$ ). The answers were summed to create a score that could range from 6 to 30, which was then categorized into tertiles: low SOC (6-20), middle SOC (21-23) and high SOC (24-30).

\section{Statistical analysis}

A Poisson regression analysis with a robust variance estimator ${ }^{37}$ was conducted to investigate the association between social participation and hypertension. In Model 1, the effects of participation in vertical and horizontal organizations on hypertension were investigated simultaneously after adjusting for age, sex, body mass index, years of education, marital status and equivalent annual income. These covariates were included in all of the subsequent models. Model 2 additionally included the provision and receiving of emotional and/or instrumental social support to/from neighbors or friends. Model 3 further adjusted for alcohol consumption and smoking status, while Model 4 included the frequency of going outside and average time spent walking each day; Model 5 included the GDS score and SOC score. The final model included all 
of the health behavior and mental health variables simultaneously (Model 6). If participants were missing information for any of the covariates, they were assigned to a 'missing' category and included in the analysis.

All statistical analyses were conducted using Stata version 13.1 (StataCorp, College Station, TX, USA). Results are presented as prevalence ratios (PR) with 95\% confidence intervals. The level of statistical significance was set at $P<0.05$ (two-tailed).

\section{Ethics approval}

The study protocol and questionnaire procedures were approved by the Ethics Committee for Research of Human Subjects at Nihon Fukushi University (ethical approval no. 10-05) and the Ethics Committee for Medical Research at the University of Tokyo (ethical approval no. 10555). Informed consent was assumed with the voluntary return of the questionnaire.

\section{RESULTS}

Characteristics of the participants

Table 1 shows the characteristics of the study participants. Among the 4582 participants, $50.2 \%$ were male. The mean age was 71.7 years, and participants had a mean body mass index of 23.1 . Nearly $60 \%$ were categorized as having hypertension. In terms of social participation, $23.9 \%$ of the respondents had participated in vertical organizations while the corresponding figure for horizontal organizations was $47.6 \%$.

\section{Social participation and hypertension}

Table 2 shows the results of the Poisson regression analysis investigating the association between social participation and hypertension. In Model 1, although participation in vertical organizations was not associated with hypertension $(P=0.40)$, participation in horizontal organizations was inversely associated with hypertension $(\mathrm{PR}=0.941$, $P=0.021$ ), with the association remaining significant after adjusting for social support $(P R=0.946, P=0.037)$. No form of social support was associated with hypertension (Model 2).

In Model 3, the inclusion of alcohol consumption and smoking status did not negate the significant association between participation in horizontal organizations and hypertension $(P=0.030)$, while alcohol consumption was also linked to hypertension; compared with people who never drank alcohol, those who consumed it every day and 4-6 days a week had a higher prevalence of hypertension ( $P R=1.125$ and 1.163, respectively). In Model 4, the inclusion of frequency of going outside and the average time spent walking each day attenuated the significant association between participating in horizontal organizations and hypertension $(P=0.068)$, while the frequency of going outside and the average time spent walking each day were both inversely associated with hypertension; participants who walked $60 \mathrm{~min}$ or more a day had a PR of 0.920 for having hypertension compared with those who walked less than $30 \mathrm{~min}$ $(P=0.007)$. Although only of borderline significance, participants who went outside one to three times a week had a PR of $0.911(P=0.064)$, compared with those who went outside less than once a month. In Model 5, the inclusion of the GDS and SOC scores did not change the significant association between participation in horizontal organizations and hypertension $(P=0.040)$, while neither the GDS nor the SOC score was associated with hypertension. In the fully adjusted Model 6, the effect of walking on hypertension was significant ( $\mathrm{PR}=0.918, P=0.006)$, whereas the association between participation in horizontal organizations and hypertension became non-significant $(P=0.057)$.

\section{DISCUSSION}

\section{Summary of findings}

This study examined the association between social participation, that is, participation in vertical and horizontal organizations and hypertension among older Japanese individuals. A Poisson regression analysis revealed that participation in horizontal organizations as measured by participation in volunteer, sports or hobby groups once a month or more often was inversely associated with hypertension. This association remained statistically significant after adjusting for emotional and instrumental social support and mental health indices, although the inclusion of certain health behavior variables in the analysis (that is, the frequency of going outside and the average time spent walking each day), attenuated the significant association. The result suggests that participation in horizontal organizations may help protect older people from hypertension and that physical activity seems to be important in this context.

Possible mechanisms linking social participation and hypertension As mentioned in the introduction, two primary pathways have been suggested as possible links between social participation and hypertension-health behavior and psychological stress. First, social participation may affect health behaviors, as individuals can receive behavioral guidance through interacting with network members, ${ }^{10,14}$ as well as engage in behaviors that promote health. Previous studies have shown, for example, that individuals with smaller social networks (for example, those living alone or with fewer transportation services available in the community) report less healthy diets ${ }^{38}$ and participate in less physical activity. ${ }^{39}$ In this study, the frequency of going outside and the average time spent walking each day, both of which might be linked to participation in organizational activities, ${ }^{12}$ were associated with a lower prevalence of hypertension (Model 4 in Table 2). In addition, it is possible that belonging to organizational groups might also extend engagement in health behavior beyond more obvious forms of outdoor exercise such as walking, for example, by increasing the frequency of shopping or simply meeting with friends. ${ }^{12}$ As the inclusion of the time spent walking and frequency of going outside variables in the analysis attenuated the significant association between horizontal organizations and hypertension and they were themselves associated with hypertension, this might indicate that participating in community organizations facilitates increased physical activity and that, in turn, this is protective against hypertension (for example, through weight $\left.\operatorname{loss}^{40}\right)$. We found that alcohol consumption did not significantly affect the association between social participation and hypertension. As alcohol consumption was positively associated with hypertension, but was also positively associated with participation in horizontal organizations (data not shown, odds ratio $=1.354$ for people who consume alcohol once a week or more $v s$. rarely or never, $P<0.001$ ), future research is needed to determine the interplay of these factors more precisely and the implications for health and well-being.

Susceptibility and reactivity to stress is a second mechanism that may link social participation and hypertension. More specifically, social participation can increase the sense of companionship and belonging among individuals, which has been associated with an enhanced ability to cope with stressors. ${ }^{10,14}$ Furthermore, social participation might also lower psychological stress as a result of increased social support obtained from people within a group. ${ }^{41,42}$ In other words, social participation may increase self-esteem or perceived social support and this can act as a buffer against psychological stressors. ${ }^{43,44}$ Given that blood pressure is elevated in the presence of psychological stress through dysfunction of the autonomic and 


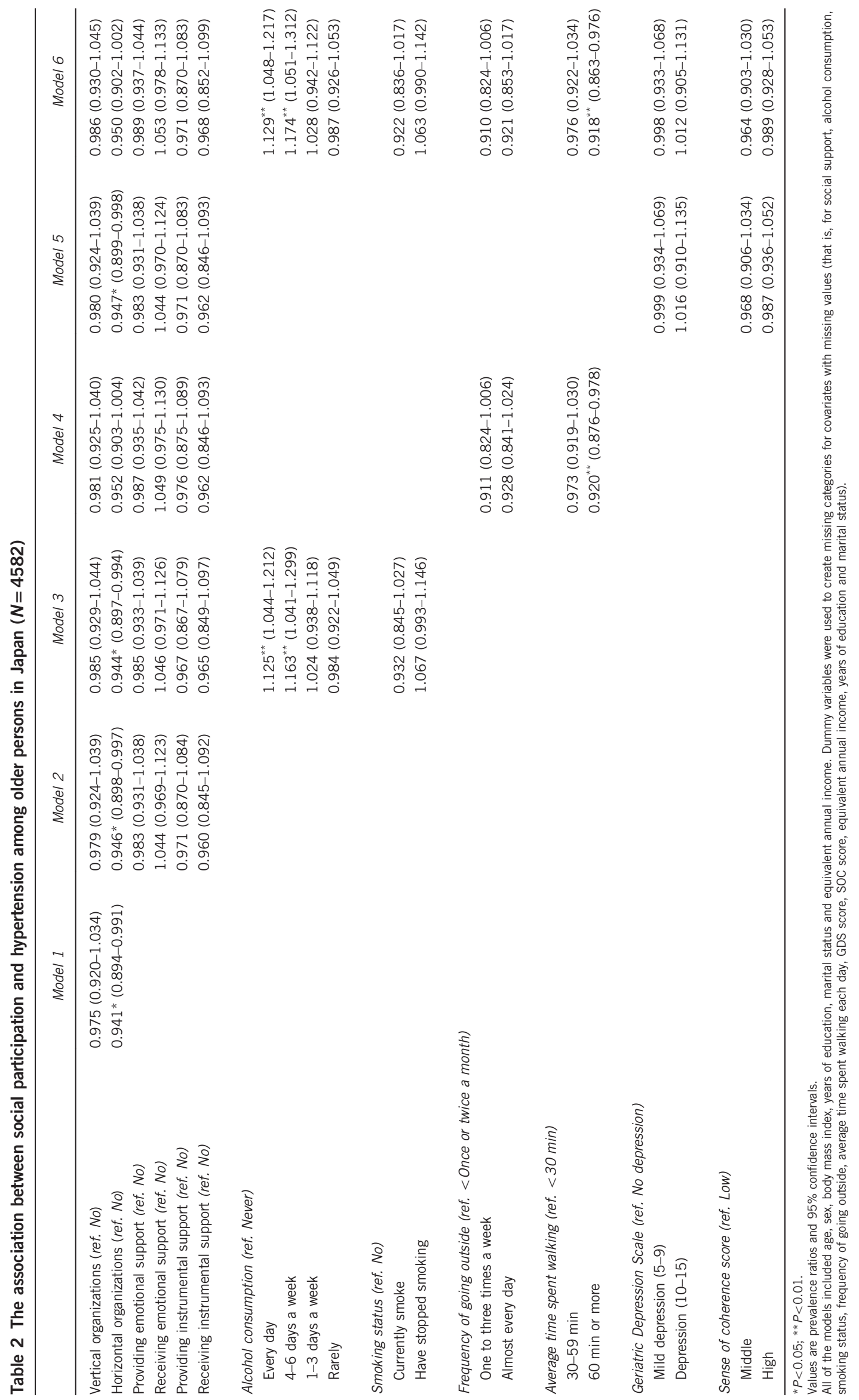


immune system, ${ }^{45}$ the stress buffering effect of social participation might protect the participants from developing hypertension. However, in this study, the GDS and SOC scores, which have been used in previous studies as proxies of psychological stress, ${ }^{46,47}$ were not associated with hypertension, and also did not attenuate the association between participation in horizontal organizations and hypertension (Model 5 in Table 2). Moreover, emotional and instrumental social support was also not associated with hypertension and had no effect on the association between participation in horizontal organizations and hypertension (Model 2 in Table 2). Although the GDS and SOC scores were not direct measures of psychological stress, these results suggest that the second pathway linking social participation and hypertension may be less important among older Japanese individuals.

\section{Different effects on hypertension: horizontal and vertical organizations}

The finding that participation in horizontal organizations is protective against hypertension accords with the results from previous research. For example, an earlier study which used data from the same cohort as in this study found that among the eight types of organization, participation in volunteer, sports or hobby groups was associated with a lower risk for all-cause mortality. ${ }^{48}$ The same authors have also shown that participation in horizontal, but not vertical organizations (defined in the same way as in this study), was protective against oral health problems. ${ }^{8}$ Kanamori et al. ${ }^{42}$ have further shown that among these eight types of organization, belonging to hobby and sports groups was protective against functional disability. It has been suggested that horizontal networks may improve the efficacy of society by facilitating coordinated action, ${ }^{49}$ while an earlier study in Japan has highlighted how such organizations enable the diffusion of healthrelated information and facilitate behaviors that promote health. ${ }^{8}$

When analyzed separately, the PRs for participating in the various horizontal organizations included in this study were $0.939(P=0.073)$ for volunteer groups, $0.983(P=0.50)$ for sports groups and 0.929 $(P=0.001)$ for hobby groups, respectively (data not shown in tables). Previous studies have found that volunteering is associated with health status/outcomes such as depressive symptoms, ${ }^{50,51}$ self-rated health, ${ }^{52}$ C-reactive protein concentration ${ }^{53}$ and also hypertension. ${ }^{54}$ Role theory has often been used to explain the health benefits of activities such as volunteering or attending meetings as they provide individuals with an opportunity to hold a meaningful social role which enables them to remain active in later life. ${ }^{53,55}$ As for hobby groups, Zawadzki et al. ${ }^{56}$ have shown that absorption in self-selected activities (that is, one's own hobbies including exercise, reading, watching TV, and so on) was related to lowered ambulatory blood pressure during an intervention study as these activities can distract people from their negative thoughts.

Participation in vertical organizations was not associated with hypertension in this study. This is in line with the results of an earlier study by Aida et al. ${ }^{8}$ that used JAGES data where it was shown that in contrast to horizontal organizations, participation in vertical organizations was not associated with dental status. An explanation for the difference between these two forms of social participation might be found in the field of social capital research as social capital (that is, 'the institutions, relationships and norms that shape the quality and frequency of social interactions ${ }^{57}$ ) is often categorized as being either vertical or horizontal in form. Putnam ${ }^{58}$ has highlighted that vertical associations may sometimes function against the formation of structural social capital, while horizontal association is essential in the formation of trust and collective action. Thus, although vertical organizations may have the potential to provide access to much bigger networks, ${ }^{59}$ it could be hypothesized that for older people who have already retired from their jobs (that is, from the strongest type of hierarchical structure across the life course) and who are living in close community-based social networks, participation in horizontal organizations may have a larger impact on individual health.

\section{Perspectives and policy implications}

Although there have been many previous attempts to control and treat hypertension in Japan, until now, most of the effort has been directed to modifying individual dietary behavior or smoking habits. The results of the current study indicate, however, that this approach alone might be insufficient in terms of reducing the prevalence of hypertension as social participation (especially participation in horizontal organizations) seems to be associated with a lower prevalence of hypertension among older people in Japan. Given the rapid aging of the population that is currently occurring and creating new challenges for maintaining health and well-being in this setting, the results from this study should serve as a scientific base for the possible expansion of social participation programs across the country to help improve the health of older people in Japan.

\section{Limitations}

There are several limitations to this study. First, although horizontal and vertical organizations were categorized in accordance with the classification used in a previous study, ${ }^{8}$ it is possible that the groups might have had both horizontal and vertical aspects. Further research is needed to establish standard measures that can be used to evaluate participation in vertical and horizontal organizations. Second, the survey response rate was $66.3 \%$. Given this, it is possible that the results may have been affected by selection bias; for example, as this was a postal survey, those who were physically incapacitated/ill might have been less likely to participate. Moreover, information on blood pressure was obtained through a municipality-managed health check-up where only approximately $38 \%$ of the older people in Japan participated in 2010. ${ }^{60}$ Third, detailed information on how blood pressure was measured in each location was not available, although the Ministry of Health, Labour and Welfare have issued guidelines for medical practitioners so that blood pressure can be measured in a standardized manner. Fourth, this study was cross-sectional, which meant causal relationships between the variables could not be established. For example, it is possible that healthy people (that is, those without hypertension) were more likely to participate in different groups (that is, there was reverse causality).

\section{CONFLICT OF INTEREST}

The authors declare no conflict of interest.

\section{ACKNOWLEDGEMENTS}

We would like to express our deep gratitude to all the people from Chita peninsula, Aichi, who participated in the JAGES survey. We also thank the other members of the JAGES study group for the constructive advice they provided during the writing of this article. This study used data from the Japan Gerontological Evaluation Study (JAGES), conducted by the Center for Well-being and Society, Nihon Fukushi University as one of their research projects, which was supported by a Health Labour Sciences Research Grant, Comprehensive Research on Aging and Health (H22-Choju-Shitei-008, H24-Junkanki (Syosyu) -Ippan-007, H24-Chikyukibo-Ippan-009, H24-Choju-Wakate-009, H25-Kenki-Wakate-015, H25-Choju-Ippan-003, H26-Irryo-Shitei-003 (Fukkou), H26-Choju-Ippan-006) from the Ministry of Health, Labour and Welfare, Japan; Grant-in-Aid for Scientific Research 
(KAKENHI) (22330172, 22390400, 23243070, 23590786, 23790710, 24390469, $24530698,24683018,25253052,25870573,25870881,15 K T 0007)$ from the Japan Society for the Promotion of Science; and a grant from National Center for Geriatrics and Gerontology, Japan (24-17, 24-23, J09KF00804).

1 World Health Organization. Cardiovascular diseases (CVDs). http://www.who.int/mediacentre/factsheets/fs317/en/. Accessed 12 November 2015.

2 Whitworth JA. World Health Organization (WHO)/International Society of Hypertension (ISH) Statement on Management of Hypertension. J Hypertens 2003; 21: 1983-1992.

3 Benetos A, Thomas F, Safar ME, Bean KE, Guize L. Should diastolic and systolic blood pressure be considered for cardiovascular risk evaluation: A study in middle-aged men and women. J Am Coll Cardiol 2001; 37: 163-168.

4 World Health Organization. A global brief of hypertension. 2013. http://apps. who.int/iris/ bitstream/10665/79059/1/WHO_DCO_WHD_2013.2_eng.pdf. Accessed 19 February 2016.

5 World Heart Fereration. Hypertension. http://www.world-heart-federation.org/cardiovascular-health/cardiovascular-disease-risk-factors/hypertension. Accessed 16 February 2016.

6 Lindstrom M, Hanson BS, Ostergren PO. Socioeconomic differences in leisure-time physical activity: The role of social participation and social capital in shaping health related behaviour. Soc Sci Med 2001; 52: 441-451.

7 World Health Organization. Global age-friendly cities: A guide. 2007. http://www.who. int/ageing/publications/Global_age_friendly_cities_Guide_English.pdf. Accessed 16 February 2016.

8 Aida J, Hanibuchi T, Nakade M, Hirai H, Osaka K, Kondo K. The different effects of vertical social capital and horizontal social capital on dental status: A multilevel analysis. Soc Sci Med 2009; 69: 512-518.

9 Umberson D, Crosnoe R, Reczek C. Social relationships and health behavior across life course. Annu Rev Sociol 2010; 36: 139.

10 Yang YC, Boen C, Mullan Harris K. Social relationships and hypertension in late life: evidence from a nationally representative longitudinal study of older adults. J Aging Health 2015; 27: 403-431.

11 House JS. Social isolation kills, but how and why? Psychosom Med 2001; 63: 273-274.

12 Tanaka C, Yoshida H, Amano H, Kumagai S, Fujiwara Y, Tsuchiya Y, Shinkai S. Physical activity level and physical, mental and social factors in community-dwelling elderly people (in Japanese). Jpn J Public Health 2006; 53: 671-680.

13 Rosenquist JN, Murabito J, Fowler JH, Christakis NA. The spread of alcohol consumption behavior in a large social network. Ann Intern Med 2010; 152: 426-433.

14 Thoits PA. Mechanisms linking social ties and support to physical and mental health $J$ Health Soc Behav 2011; 52: 145-161.

15 Berkman LF, Syme SL. Social networks, host resistance, and mortality: A nine-year follow-up study of alameda county residents. Am J Epidemiol 1979; 109: 186-204.

16 Bygren LO, Konlaan BB, Johansson SE. Attendance at cultural events, reading books or periodicals, and making music or singing in a choir as determinants for survival: Swedish interview survey of living conditions. BMJ 1996; 313: 1577-1580.

17 Dalgard OS, Lund Haheim L. Psychosocial risk factors and mortality: a prospective study with special focus on social support, social participation, and locus of control in norway. J Epidemiol Community Health 1998; 52: 476-481.

18 Glass TA, de Leon CM, Marottoli RA, Berkman LF. Population based study of social and productive activities as predictors of survival among elderly americans. BMJ 1999; 319: 478-483.

19 Hyyppa MT, Maki J, Impivaara O, Aromaa A. Leisure participation predicts survival: A population-based study in finland. Health Promot Int 2006; 21: 5-12.

20 Hyyppa MT, Maki J. Social participation and health in a community rich in stock of social capital. Health Educ Res 2003; 18: 770-779.

21 Hyyppa MT, Maki J. Individual-level relationships between social capital and self-rated health in a bilingual community. Prev Med 2001; 32: 148-155.

22 Veenstra G. Social capital, ses and health: an individual-level analysis. Soc Sci Med 2000; 50: 619-629.

23 Ellaway A, Macintyre S. Social capital and self-rated health: Support for a contextual mechanism. Am J Public Health 2000; 90: 988.

24 Greiner KA, Li C, Kawachi I, Hunt DC, Ahluwalia JS. The relationships of social participation and community ratings to health and health behaviors in areas with high and low population density. Soc Sci Med 2004; 59: 2303-2312.

25 Kamiya Y, Whelan B, Timonen V, Kenny RA. The differential impact of subjective and objective aspects of social engagement on cardiovascular risk factors. BMC Geriatr 2010; 10: 81.

26 Shankar A, McMunn A, Banks J, Steptoe A. Loneliness, social isolation, and behavioral and biological health indicators in older adults. Health Psychol 2011; 30: 377-385.

27 Muennig P, Cohen AK, Palmer A, Zhu W. The relationship between five different measures of structural social capital, medical examination outcomes, and mortality. Soc Sci Med 2013; 85: 18-26.

28 Reddy KS. Cardiovascular disease in non-western countries. N Engl J Med 2004; 350: 2438-2510.

29 Cabinet Office Government of Japan. General principles concerning measures for the aged society (in Japanese). 2016. http://www8.cao.go.jp/kourei/english/measure/etaiko2.html. Available 16 February 2016.
30 Ministry of Health Labor and Welfare Japan. General concept for standard health checkup and counseling guidance (in Japanese). 2007. http://www.mhlw.go.jp/bunya/ shakaihosho/iryouseido01/pdf/tdfk15-02.pdf. Accessed 20 January 2016.

31 The Japanese Society of Hypertension. Gudelines for the management of hypertension 2014 (in Japanese). 2014. http://www.jpnsh.jp/data/jsh2014/jsh2014v1_1.pdf. Accessed 16 February 2016.

32 Saito M, Kondo K, Ojima T. Criteria for social isolation based on associations with health indicators among older people a 10-year follow-up of the aichi gerontological evaluation study. Jpn J Public Health 2015; 62: 95-105.

33 Burke WJ, Roccaforte WH, Wengel SP. The short form of the geriatric depression scale: A comparison with the 30-item form. J Geriatr Psychiatry Neurol 1991; 4: 173-178.

34 Hintermair M. Sense of coherence: A relevant resource in the coping process of mothers of deaf and hard-of-hearing children? J Deaf Stud Deaf Educ 2004; 9: 15-26.

35 Lindfors $\mathrm{P}$, Lundberg $\mathrm{O}$, Lundberg $\mathrm{U}$. Sense of coherence and biomarkers of health in 43-year-old women. Int J Behav Med 2005; 12: 98-102.

36 Antonovsky A. Unraveling the Mystery of Health: How People Manage Stress and Stay Well. Jossey-Bass: San Francisco, CA, USA. 1987.

37 Barlow WE. Robust variance estimation for the case-cohort design. Biometrics 1994; 50: 1064-1072.

38 Locher JL, Ritchie CS, Roth DL, Baker PS, Bodner EV, Allman RM. Social isolation, support, and capital and nutritional risk in an older sample: Ethnic and gender differences. Soc Sci Med 2005; 60: 747-761.

39 Kharicha K, Iliffe S, Harari D, Swift C, Gillmann G, Stuck AE. Health risk appraisal in older people 1: Are older people living alone an 'at-risk' group? Br J Gen Pract 2007; 57: 271-276.

40 Kawamoto R, Kohara K, Katoh T, Kusunoki T, Ohtsuka N, Abe M, Kumagi T, Miki T. Effect of weight loss on central systolic blood pressure in elderly community-dwelling persons. Hypertens Res 2014; 37: 933-938.

41 Malecki CK, Demary MK. Measuring perceived social support: Development of the child and adolescent social support scale (casss). Psychol Sch 2001; 39: 1-18.

42 Kanamori S, Kai Y, Aida J, Kondo K, Kawachi I, Hirai H, Shirai K, Ishikawa Y, Suzuki K, The JAGES Group. Social participation and the prevention of functional disability in older japanese: The JAGES Cohort Study. PLOS ONE 2014; 9: e99638.

43 Ozbay F, Johnson DC, Dimoulas E, Morgan CA, Charney D, Southwick S. Social support and resilience to stress: From neurobiology to clinical practice. Psychiatry (Edgmont) 2007; 4: 35-40.

44 Cohen S, McKay G. Social support, stress and the buffering hypothesis: A theoretical analysis. Handbook of psychology and health. Erlbaum: Hillsdale, NJ, USA, 1984; 4: 253-267.

45 Brosschot JF, Gerin W, Thayer JF. The perseverative cognition hypothesis: A review of worry, prolonged stress-related physiological activation, and health. J Psychosom Res 2006; 60: 113-124.

46 Wongpakaran N, Wongpakaran T, Wannarit K, Saisavoey N, Pinyopornpanish M, Lueboonthavatchai P, Apisiridej N, Srichan T, Ruktrakul R, Satthapisit S, Nakawiro D, Hiranyatheb T, Temboonkiat A, Tubtimtong N, Rakkhajeekul S, Wongtanoi B, Tanchakvaranont S, Bookkamana P, Srisutasanavong U, Nivataphand R, Petchsuwan D. Level of agreement between self-rated and clinician-rated instruments when measuring major depressive disorder in the thai elderly: A 1-year assessment as part of the thaisad study. Clin Interv Aging 2014; 9: 377-382.

47 Peker K, Bermek G, Uysal O. Factors related to sense of coherence among dental students at istanbul university. J Dent Educ 2012; 76: 774-782.

48 Aida J, Kondo K, Hirai H, Subramanian SV, Murata C, Kondo N, Ichida Y, Shirai K, Osaka K. Assessing the association between all-cause mortality and multiple aspects of individual social capital among the older japanese. BMC Public Health 2011; 11: 499.

49 Putnam RD, Leonardi R, Nanetti RY. Making democracy work: Civic traditions in modern italy. Princeton university press: Princeton, NJ, USA, 1994.

50 Musick MA, Wilson J. Volunteering and depression: The role of psychological and social resources in different age groups. Soc Sci Med 2003; 56: 259-269.

$51 \mathrm{Li} \mathrm{Y,} \mathrm{Ferraro} \mathrm{KF.} \mathrm{Volunteering} \mathrm{and} \mathrm{depression} \mathrm{in} \mathrm{later} \mathrm{life:} \mathrm{Social} \mathrm{benefit} \mathrm{or} \mathrm{selection}$ processes? J Health Soc Behav 2005; 46: 68-84.

52 Lum TY, Lightfoot $E$. The effects of volunteering on the physical and mental health of older people. Res Aging 2005; 27: 31-55.

$53 \mathrm{Kim}$ S, Ferraro KF. Do productive activities reduce inflammation in later life? Multiple roles, frequency of activities, and c-reactive protein. Gerontologist 2014; 54: 830-839.

54 Tavares JL, Burr JA, Mutchler JE. Race differences in the relationship between formal volunteering and hypertension. J Gerontol B Psychol Sci Soc Sci 2013; 68: 310-319.

55 Thoits PA. Role-identity salience, purpose and meaning in life, and well-being among volunteers. Soc Psychol Q 2012; 75: 360-384.

56 Zawadzki MJ, Smyth JM, Merritt MM, Gerin W. Absorption in self-selected activities is associated with lower ambulatory blood pressure but not for high trait ruminators. Am J Hypertens 2013; 26: 1273-1279.

57 Bourdieu P. The forms of capital (1986) . Readings in Economic Sociology 2008; 4: 280-291.

58 Putnam RD. Democracies in flux: The evolution of social capital in contemporary society. Oxford University Press: Oxford, UK, 2002.

59 Engstrom K, Mattsson F, Jarleborg A, Hallqvist J. Contextual social capital as a risk factor for poor self-rated health: A multilevel analysis. Soc Sci Med 2008; 66: 2268-2280.

60 Ministry of Health Labor and Welfare Japan, Implemantation status report of the municipality-managed health examination (the Tokutei Kenkou Shinsa) and health education (the Tokutei Kenkou Shidou) in 2010 (in Japanese). 2010. http://www.mhlw. go.jp/bunya/shakaihosho/iryouseido01/dl//info03 h22 02.pdf. Accessed 12 February 2016. 